\title{
Apolipoprotein $\mathbf{E}$ genotype modulates the effect of black tea drinking on blood lipids and blood coagulation factors: a pilot study
}

\author{
Alexandre Loktionov ${ }^{1 *}$, Sheila A. Bingham ${ }^{1}$, Hester Vorster ${ }^{2}$, Johann C. Jerling ${ }^{2}$, Shirley A. Runswick ${ }^{1}$ \\ and John H. Cummings ${ }^{1}$ \\ ${ }^{1}$ Medical Research Council, Dunn Clinical Nutrition Centre, Hills Road, Cambridge CB2 2DH, UK \\ ${ }^{2}$ Department of Nutrition, Potchefstroom University for Christian Higher Education, Potchefstroom, South Africa
}

(Received 18 June 1997 - Revised 17 September 1997 - Accepted 22 September 1997)

\begin{abstract}
Apolipoprotein E (ApoE) genotype was determined in sixty-five subjects who had taken part in a 4-week randomized crossover trial to compare the effect of six mugs of black tea per day $v$. placebo on blood lipids and blood coagulation factors. Four ApoE genotype variants (seven E2/E3, forty-five E3/E3, twelve E3/E4 and one E4/E4) were found. ApoE allele frequency was within the range typical for Caucasian populations (ApoE-E2 5.4\%; ApoE-E3 83.8\%; ApoE-E4 $10.8 \%$ ). Individuals bearing at least one $\mathrm{E} 4$ allele had substantially higher levels of serum total cholesterol, LDL cholesterol and triacylglycerols. Mean plasminogen activator inhibitor (PAI-1) activity was higher in ApoE-E4 allele-bearing individuals (E3/E4 + E4/E4, 11.89 (SE 1.27) U/ml; E3/E3, 9.19 (SE 0.80) U/ml; E2/E3, 7.21 (SE 1.04) U/ml, $P$ values of E4-group $v$. E3 and E2 being respectively 0.093 and 0.030 ). These unexpected findings imply that elevated PAI-1 activity may be a hitherto unrecognized additional factor involved in the increased cardiovascular disease risk associated with apoE-E4 allele. The interactions between tea drinking and genotype were also examined. In the E3/E3 homozygotes, HDL-cholesterol was significantly reduced in the tea period (mean placebo $1.54 \mathrm{mmol} / 1 \mathrm{v}$. mean tea $1.50 \mathrm{mmol} / \mathrm{l}$, $P=0.027$ ). In the E2/E3 group, triacylglycerol concentration was significantly reduced (mean placebo $1.18 \mathrm{mmol} / 1 \mathrm{v}$. mean tea $1.09 \mathrm{mmol} / 1, P=0.039$ ). Tea also caused a significant decrease of PAI-1 activity in the subjects with E2/E3 genotype (mean placebo $7.21 \mathrm{U} / \mathrm{ml} v$. mean tea $5.88 \mathrm{U} / \mathrm{ml}, P=0.007$ ). In the other two genotype groups, there was no significant effect of tea. The results indicate that tea drinking has a beneficial effect on some cardiovascular disease risk-associated factors, especially in E2 allele-bearing individuals. Dietary intervention may be particularly effective in population groups with certain genetic characteristics.
\end{abstract}

Apolipoproteins: Cardiovascular disease: Genotype: Dietary intervention: Tea

There are a number of well-established dietary factors in the pathogenesis of atherosclerosis and resulting cardiovascular disease (Department of Health, 1994). However not all individuals respond to measures expected to reduce serum lipids and other cardiovascular disease risk factors. This is probably due to the presence of different genetic variants in human populations.

Apolipoprotein $\mathrm{E}$ (ApoE) is one of the major factors in lipid metabolism in man. There are three common isoforms of the protein corresponding to alleles APOE*2 (E2), APOE*3 (E3), and APOE*4 (E4) encoded by a single locus in chromosome 19 (Davignon et al. 1988; Mahley, 1988).
E3, which is the most frequent allele, has Cys at position 112 and Arg at position 158, E2 has Cys at position 158, and E4 has Arg at position 112. These differences in the gene sequence cause structural changes strongly affecting binding properties of the corresponding ApoE isoforms. Protein products of E3 and E2 display a preference for HDL, whereas ApoE4 preferentially binds to VLDL (Weisgraber \& Mahley, 1996). The latter preference is believed to be the main factor in the association of ApoE4 with elevated concentrations of plasma cholesterol and LDL, and an increased risk for cardiovascular disease (Davignon et al. 1988). Indeed, the presence of the $\mathrm{E} 4$

Abbreviations: Apo, apolipoprotein; bp, base pairs; PAI-1, plasminogen activator inhibitor-1; tPA, tissue-type plasminogen activator. *Corresponding author: Dr A. Loktionov, fax + 44 (0) 1223 413763, email Alex.Loktionov@mrc-dunn.cam.ac.uk 
allele is now considered to be the most common genetic abnormality in atherosclerosis (Wilson et al. 1994; Castelli, 1996) and has been demonstrated to be an important risk factor for heart disease in a number of human populations (Wilson et al. 1994; Kamboh et al. 1995; Scheer et al. 1995; Nakata et al. 1996; Wilson et al. 1996). It has also been reported that individuals bearing different alleles of the ApoE gene may respond differently to dietary interventions intended to normalize blood lipid concentrations (Xu et al. 1990; Manttari et al. 1991; Marshall et al. 1996; Routi et al. 1996).

The current paper presents the results of a reanalysis of a previously published study of the effect of tea drinking on blood lipid concentrations and blood coagulation factors. This was performed to test the hypothesis that black tea might alter blood cholesterol levels and two other cardiovascular disease risk factors, blood clotting and blood pressure (Vorster et al. 1996; Bingham et al. 1997). Although that study failed to reveal any substantial effect of tea drinking, in order to unveil possible genotype-related response patterns we decided to determine ApoE genotypes of the participating subjects. Moreover the relationship between ApoE genotype and blood clotting factors has not previously been investigated.

\section{Methods}

\section{Subjects and protocol}

The subjects were sixty-five clinically healthy people including thirty-one men and thirty-four women aged 20 73 years. The 10 -week study was divided into a 2 -week run-in period, 4 weeks with tea and then a crossover of 4 weeks without tea (placebo period). The placebo consisted of water, caffeine, milk and sugar. To avoid order effects, subjects were randomly assigned to tea or placebo first. Throughout the course of the study, measurements were made of diet, fluid intakes, weight and blood pressure, and blood and urine were collected. A detailed description of the study protocol has been given elsewhere (Bingham et al. 1997). In the present study the data obtained during weeks 2, 3 and 4 of tea and placebo periods were used for analysis. The placebo data were used for cross-sectional comparisons between different genotype groups since this period would have been unaffected by tea.

\section{Blood collection and analysis}

Each volunteer gave a $10 \mathrm{ml}$ blood sample at the Dunn Clinical Nutrition Centre at the time of the initial medical, at the end of the 2-week run-in period and at the end of the 2nd, $3 \mathrm{rd}$ and 4 th weeks of each test period. Blood was taken in monovettes after a $12 \mathrm{~h}$ fast. Serum and cell fractions (buffy coats) were separated by centrifugation. Serum was stored at $-20^{\circ}$ before analysis for total cholesterol, measured after enzymic hydrolysis and oxidation, HDLcholesterol by precipitation of LDL, VLDL and chylomicrons, and triacylglycerols after enzymic hydrolysis with lipases. Randox packs (Randox Laboratories Ltd, Crumlin, Northern Ireland, UK) were used for all these analyses using the Roche Cobas Fara system (Roche, Welwyn
Garden City, Herts, UK). All seven samples from each individual were analyzed on the same run, and results from only those runs with control serum results which were within the recommended External Quality Assurance Scheme range (mean $\pm 2 \mathrm{SD}$ ) were used. Citrated plasma $(1: 9 \mathrm{v} / \mathrm{v})$ was analysed for fibrinogen (Clauss, 1957) using reagents, standards and control plasmas from Behringwerke, Marburg, Germany. Plasma plasminogen activator inhibitor-1 (PAI-1) antigen was measured by ELISA (Tint Elize PAI-1), PAI-1 activity by an indirect enzymic method (Spectrolyse $\mathrm{pL}$ ), and tissue-type plasminogen activator (tPA) antigen by ELISA (Imulyse tPA), all from Biopool, Umea, Sweden. Appropriate calibration and control plasmas were used (Vorster et al. 1996). The intra-assay $\mathrm{CV}$ for these methods varied from 1.6 to $5.8 \%$. Due to initial problems with the blood collection protocol blood coagulation factors were studied only in 57 subjects (Vorster et al. 1996).

\section{ApoE genotype determination}

The subjects were genotyped using an original modification of the existing approach based on the principle of detecting polymorphic sites of the ApoE gene DNA sequence with Hhal digestion (Hixson \& Vernier, 1990; Kontula et al. 1990; Wenham et al. 1991; Kamboh et al. 1995). Genomic DNA was extracted from EDTA-treated blood with QIAmp Blood Kit (Quiagen Ltd, Dorking, Surrey, UK). Primers $5^{\prime}$-CCCTCTCGGCCGCAGGGCGCTGAT-3' and $5^{\prime}$ GGTCCGGCTGCCCATCTCCTCCAT-3' flanking polymorphic exon 4 region of the ApoE gene (Paik et al. 1985) were used for amplification of a 508 base pair (bp) fragment. The primers were designed using MacDNASIS Sequence Analysis Software (Hitachi, Japan). The polymerase chain reaction mixture $(50 \mu \mathrm{l})$ included $500 \mathrm{ng}$ DNA with $10 \mathrm{mM}-$ Tris- $\mathrm{HCl}$, pH $8.3,50 \mathrm{mM}-\mathrm{KCl}, 7.5 \mathrm{mM}$ $\mathrm{MgCl}_{2}, 100 \mathrm{ml} / 1$ dimethylsulfoxide, $100 \mu \mathrm{M}$ of each deoxynucleoside triphosphate, and $0.5 \mu \mathrm{M}$ of each primer. Mineral oil was applied over the mixture to prevent evaporation. At the initial stage the 'hot start' technique was employed, i.e. $1 \mathrm{U}$ of AmpliTaq DNA Polymerase (Perkin Elmer Cetus Inc., Foster City, CA, USA) was added to each tube preheated to $80^{\circ}$. Initial denaturation for $3 \mathrm{~min}$ at $94^{\circ}$ was followed by thirty-five cycles of denaturation at $94^{\circ}$ for $1 \mathrm{~min}$ and annealling/extension at $69^{\circ}$ for $1 \mathrm{~min}$. Amplification was performed using a PTC100 thermocycler (MJ Research, Inc., Watertown, MA, USA). The resulting amplified fragment was restricted directly with 5 units of Hhal (New England Biolabs, Beverly, MA, USA) for $2 \mathrm{~h}$. The digested DNA fragments were separated on nondenaturing polyacrylamide gel $(100 \mathrm{~g} / \mathrm{l})$, stained with ethidium bromide and visualized under u.v. light. Additional HhaI restriction sites located throughout the amplified sequence do not interfere with the polymorphism detection since the five diagnostically important fragments of $91 \mathrm{bp}$ (indicates presence of E2 or E3 allele), $83 \mathrm{bp}$ (indicates presence of $\mathrm{E} 2$ allele), $72 \mathrm{bp}$ (indicates presence of E4 allele), $48 \mathrm{bp}$ (indicates presence of E3 or E4 allele) and $35 \mathrm{bp}$ (indicates presence of E3 or E4 allele) are unique and easily identifiable (see Fig. 1). 


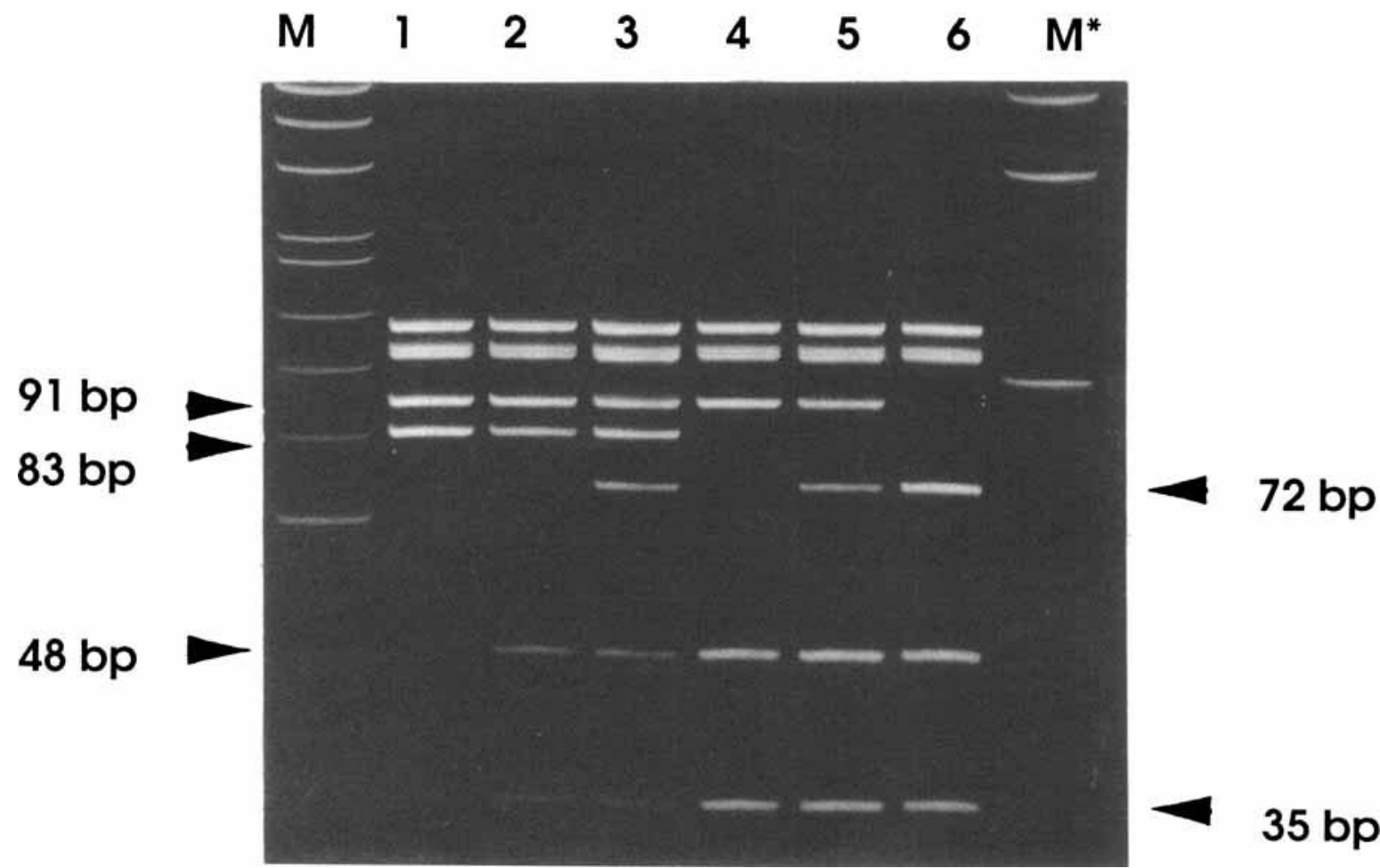

Flg. 1. Apolipoprotein E genotype determination by $H$ hal restriction of the 508 bp amplified fragment. Lanes: (M) molecular mass marker phiX174

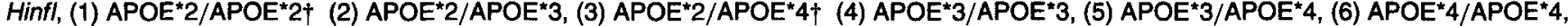
$\left(M^{*}\right)$ molecular mass marker $100 \mathrm{bp}$ ladder. $\rightarrow$ positions of the five diagnostically important fragments. Note band intensity difference between homozygous and heterozygous samples. † These DNA specimens were taken from a different set of samples since no individuals with such genotypes were found among subjects of the present study.

\section{Statistics}

All results are expressed as the mean and standard error (SE). Paired $t$ tests were carried out using mean values for placebo and tea periods from each participant. Paired and unpaired $t$ tests, and all other analyses were conducted using Systat 5.2 (Systat, Evanston, IL, USA) and Data Desk $^{4}$ (Data Description, Inc., Ithaca, NY, USA) statistical packages.

\section{Results}

\section{ApoE genotype determination and allele distribution}

All three common alleles of ApoE were detected among the study subjects. As expected, the most frequent genotype detected was E3/E3 (forty-five subjects, $69 \%$ ) followed by E3/E4 (twelve subjects, 18\%), E2/E3 (seven subjects, $11 \%$ ) and E4/E4 (one subject, $2 \%$ ). No E2/E2 or E2/E4 variants were found. The allele distribution was as follows: E2 $5.4 \%$; E3 $83.8 \%$; E4, $10.8 \%$. Using these results, further analyses were carried out for three genotype-based groups: (a) individuals bearing an E2 allele (E2/E3 genotype, three males and four females); (b) individuals bearing only E3 alleles (E3/E3 homozygotes, twenty males and twenty-five females); (c) individuals bearing at least one $\mathrm{E} 4$ allele (E3/E4 + E4/E4 genotype, eight males and five females).

\section{General variables including smoking, diet and blood pressure}

Age distributions within the new groups were similar (E2/E3, 41.2 (SE 11.2) years; E3/E3, 39.2 (SE 15.6) years; E3/E4 +E4/E4, 45.3 (SD 12.8) years. Less than $50 \%$ of each group were smokers (E2/E3, $43 \%$; E3/E3, $33 \%$; E3/E4 + E4/E4, 46\%). There were no differences in the consumption of the major nutrients (including fatty acids) between the genotype groups and between the tea and placebo periods within the groups (results not shown).

No significant differences were detected between diastolic blood pressures measured during the placebo period in the three genotype groups; mean values were 71.7 (SE 1.8 ) $\mathrm{mmHg}$ for E2/E3, 75.2 (SE 1.4) $\mathrm{mmHg}$ for E3/E3 and 76.4 (SE 1.7) $\mathrm{mmHg}$ for E3/E4 + E4/E4 subjects. The respective systolic blood pressure values were 120.1 (SE 5.4) $\mathrm{mmHg}$ for $\mathrm{E} 2 / \mathrm{E} 3,118.3$ (SE 2.0 ) $\mathrm{mmHg}$ for $\mathrm{E} 3 / \mathrm{E} 3$ and 124.5 (SE 2.6) $\mathrm{mmHg}$ for $\mathrm{E} 3 / \mathrm{E} 4+\mathrm{E} 4 / \mathrm{E} 4$ individuals. Tea drinking did not result in any significant change in these values in all the three groups (results not shown).

\section{Blood lipids}

Table 1 shows mean values of total cholesterol, LDLcholesterol, HDL-cholesterol and triacylglycerol in the different genotype groups during the two periods of the 
Table 1. Serum total cholesterol, LDL-cholesterol, HDL-cholesterol and triacylglycerol concentrations of subjects drinking six mugs of black tea or a placebo daily, and in subgroups determined by apolipoprotein E genotype*

(Mean values with their standard errors for all sixty-five participants and for the genotype subgroups)

\begin{tabular}{|c|c|c|c|c|c|}
\hline & \multicolumn{2}{|c|}{ Placebo } & \multicolumn{2}{|c|}{ Tea } & \multirow{2}{*}{$\begin{array}{c}P \\
\text { (Placebo v. tea) }\end{array}$} \\
\hline & Mean & SE & Mean & SE & \\
\hline \multicolumn{6}{|c|}{ Total cholesterol $(\mathrm{mmol} / \mathrm{l})$} \\
\hline $\begin{array}{l}\text { Total }(n 65) \\
\text { E2/E3 }(n 7) \\
\text { E3/E3 }(n 45) \\
\text { E4 + }(n 13)\end{array}$ & $\begin{array}{l}5.76 \\
5.55 \\
5.59 \\
6.47\end{array}$ & $\begin{array}{l}0.14 \\
0.53 \\
0.16 \\
0.27\end{array}$ & $\begin{array}{l}5.69 \\
5.44 \\
5.50 \\
6.51\end{array}$ & $\begin{array}{l}0.13 \\
0.45 \\
0.15 \\
0.25\end{array}$ & $\begin{array}{l}0.154 \\
0.652 \\
0.087 \\
0.719\end{array}$ \\
\hline \multicolumn{6}{|c|}{ LDL-cholesterol (mmol/l) } \\
\hline $\begin{array}{l}\text { Total }(n 65) \\
\text { E2/E3 }(n 7) \\
\text { E3/E3 }(n 45) \\
\text { E4 }+(n 13)\end{array}$ & $\begin{array}{l}3.53 \\
3.24 \\
3.39 \\
4.17\end{array}$ & $\begin{array}{l}0.16 \\
0.68 \\
0.19 \\
0.32\end{array}$ & $\begin{array}{l}3.48 \\
3.06 \\
3.34 \\
4.21\end{array}$ & $\begin{array}{l}0.16 \\
0.64 \\
0.18 \\
0.29\end{array}$ & $\begin{array}{l}0.200 \\
0.299 \\
0.299 \\
0.721\end{array}$ \\
\hline \multicolumn{6}{|c|}{ HDL-cholesterol $(\mathrm{mmol} / \mathrm{l})$} \\
\hline $\begin{array}{l}\text { Total }(n 65) \\
\text { E2/E3 }(n 7) \\
\text { E3/E3 }(n 45) \\
\text { E4+ }(n 13)\end{array}$ & $\begin{array}{l}1.52 \\
1.48 \\
1.54 \\
1.46\end{array}$ & $\begin{array}{l}0.05 \\
0.20 \\
0.07 \\
0.09\end{array}$ & $\begin{array}{l}1.49 \\
1.62 \\
1.50 \\
1.43\end{array}$ & $\begin{array}{l}0.05 \\
0.22 \\
0.06 \\
0.10\end{array}$ & $\begin{array}{l}0.198 \\
0.123 \\
0.027 \\
0.297\end{array}$ \\
\hline \multicolumn{6}{|c|}{ Triacylglycerols $(\mathrm{mmol} /)$} \\
\hline $\begin{array}{l}\text { Total }(n 65) \\
\text { E2/E3 (n 7) } \\
\text { E3/E3 (n 45) } \\
\text { E4+ (n 13) }\end{array}$ & $\begin{array}{l}1.27 \\
1.18 \\
1.21 \\
1.67\end{array}$ & $\begin{array}{l}0.08 \\
0.22 \\
0.09 \\
0.20\end{array}$ & $\begin{array}{l}1.28 \\
1.09 \\
1.24 \\
1.67\end{array}$ & $\begin{array}{l}0.08 \\
0.22 \\
0.09 \\
0.19\end{array}$ & $\begin{array}{l}0.770 \\
0.039 \\
0.524 \\
0.871\end{array}$ \\
\hline
\end{tabular}

- For details of procedures and genotype subgroups, see pp. 134-135.

study. Results obtained during the placebo period show that individuals bearing at least one $\mathrm{E} 4$ allele had a significantly higher concentration of total serum cholesterol compared with the E3/E3 group $(P=0.008)$. The difference between the E4- and E2-bearing subjects failed to reach statistical significance $(P=0.098)$. E3/E4 + E4/E4 $v$. E3/E3 comparisons revealed significant differences for both LDLcholesterol $(P=0.048)$ and triacylglycerols $(P=0.025)$. HDL-cholesterol concentrations were similar in all the genotype groups.

Paired $t$ tests showed no statistically significant difference in total cholesterol between placebo and tea periods in any of the ApoE genotype groups. HDL-cholesterol concentrations were significantly decreased in E3/E3 subjects, during the tea drinking period by $0.04 \mathrm{mmol} / 1$ $(P=0.027)$. Tea drinking also significantly decreased triacylglycerol concentrations in E2/E3 subjects from 1.18 (SE 0.22 ) mmol/l to 1.09 (SE 0.22 ) mmol/l $(P=0.039)$. There was no effect in the other groups.

\section{Blood coagulation factors}

Results of measurements of blood coagulation factors in the different genotype groups are shown in Table 2 . The highest concentrations of plasma fibrinogen were found in subjects with E2/E3 genotype (3.41 (SE 0.19) g/l, $P=0.043$ when compared with E3/E3 homozygotes). There was substantial variation in IPA antigen concentrations (see Table 2), and no significant difference between the groups was detected. Determination of PAI-1 activity showed that individuals with the ApoE-E4 alleles had
Table 2. Concentrations or activities of blood coagulation factors including plasma fibrinogen, tissue-type plasminogen activator antigen (tPA antigen) plasminogen activator inhibitor-1 (PAl-1) activity and $\mathrm{PAl}-1$ antigen in subjects drinking six mugs of black tea or a placebo daily, and in subgroups determined by apolipoprotein E genotype*

(Mean values with their standard errors for all sixty-five $\dagger$ participants and for the genotype subgroups)

\begin{tabular}{|c|c|c|c|c|c|}
\hline & \multicolumn{2}{|c|}{ Placebo } & \multicolumn{2}{|c|}{ Tea } & \multirow{2}{*}{$\begin{array}{c}P \\
(\text { placebo v. tea })\end{array}$} \\
\hline & Mean & SE & Mean & SE & \\
\hline $\begin{array}{l}\text { Fibrinogen (g/l } \\
\text { Total }(n 57) \\
\text { E2/E3 }(n 6) \\
\text { E3/E3 }(n 39) \\
\text { E4+ }(n 12)\end{array}$ & $\begin{array}{l}2.90 \\
3.41 \\
2.84 \\
2.85\end{array}$ & $\begin{array}{l}0.08 \\
0.19 \\
0.10 \\
0.17\end{array}$ & $\begin{array}{l}2.89 \\
3.43 \\
2.85 \\
2.74\end{array}$ & $\begin{array}{l}0.09 \\
0.13 \\
0.11 \\
0.21\end{array}$ & $\begin{array}{l}0.843 \\
0.920 \\
0.971 \\
0.450\end{array}$ \\
\hline $\begin{array}{l}\text { tPA antigen (n) } \\
\text { Total }(n 49) \\
\text { E2/E3 }(n 5) \\
\text { E3/E3 }(n 35) \\
\text { E4+ }(n 9)\end{array}$ & $\begin{array}{l}\mathrm{g} / \mathrm{ml}) \\
5.34 \\
5.39 \\
5.13 \\
6.17\end{array}$ & $\begin{array}{l}0.36 \\
0.84 \\
0.42 \\
1.06\end{array}$ & $\begin{array}{l}5.40 \\
5.37 \\
5.40 \\
5.44\end{array}$ & $\begin{array}{l}0.34 \\
0.85 \\
0.43 \\
0.77\end{array}$ & $\begin{array}{l}0.746 \\
0.985 \\
0.208 \\
0.069\end{array}$ \\
\hline $\begin{array}{l}\text { PAl-1 activity ( } \\
\text { Total }(n 54) \\
\text { E2/E3 }(n 6) \\
\text { E3/E3 }(n 36) \\
\text { E4+ }(n 12)\end{array}$ & $\begin{array}{l}\mathrm{U} / \mathrm{ml}) \\
9.56 \\
7.21 \\
9.19 \\
11.89\end{array}$ & $\begin{array}{l}0.63 \\
1.04 \\
0.80 \\
1.27\end{array}$ & $\begin{array}{r}9.13 \\
5.88 \\
9.36 \\
10.04\end{array}$ & $\begin{array}{l}0.73 \\
0.84 \\
0.86 \\
1.98\end{array}$ & $\begin{array}{l}0.335 \\
0.007 \\
0.914 \\
0.102\end{array}$ \\
\hline $\begin{array}{l}\text { PAl-1 antigen } \\
\text { Total ( } n 57) \\
\text { E2/E3 }(n 6) \\
\text { E3/E3 }(n \text { 39) } \\
\text { E4+ }(n 12)\end{array}$ & $\begin{array}{r}\text { (ng/ml) } \\
40.77 \\
39.50 \\
40.90 \\
40.98\end{array}$ & $\begin{array}{l}1.63 \\
6.03 \\
2.02 \\
3.23\end{array}$ & $\begin{array}{l}41.67 \\
36.58 \\
41.34 \\
45.28\end{array}$ & $\begin{array}{l}1.94 \\
3.42 \\
2.58 \\
3.41\end{array}$ & $\begin{array}{l}0.662 \\
0.577 \\
0.868 \\
0.304\end{array}$ \\
\hline
\end{tabular}

- For details of procedures and genotype subgroups, see pp. 134-135.

† Samples from some subjects were not available for all the assays. For this reason both total numbers of subjects analysed and numbers of subjects analysed within genotype groups may differ.

higher levels than those of other groups. Average PAI-1 activity found in subjects with E4 was 11.89 (SE 1.27) U/ml (E3/E3 9.19 (SE 0.80) U/ml; E2/E3 7.21 (SE $1.04) \mathrm{U} / \mathrm{ml}$ ). $P$ values from comparisons of E4-groups with E3 and E2 were respectively 0.093 and 0.030 . PAI-1 antigen levels were at the same level in all study groups.

Table 2 shows the results of measurements of the blood clotting factors during placebo and tea periods. No effect of tea drinking on serum fibrinogen concentration was evident in any genotype group. The trend towards a decrease in IPA antigen concentration from 6.17 (SE 1.06) ng/ml to 5.44 (SE $0.77) \mathrm{ng} / \mathrm{ml}$ observed in the $\mathrm{E} 3 / \mathrm{E} 4+\mathrm{E} 4 / \mathrm{E} 4$ group during tea drinking failed to reach statistical significance $(P=0.069)$. There was also no change in the E3/E3 and E2/E2 groups. However, significant differences between the study groups were seen when PAI-1 activities for the two study periods were compared (see Table 2). An $18.4 \%$ decrease in PAI-1 activity was detected in the E2/E3 group $(P=0.007)$. In all the tested subjects of this group, tea drinking lowered PAI-1 activity. The individual responses ranged from 4.1 to $29.7 \%$ (Fig. 2(a)). The same trend was observed for the most of E3/E4 + E4/E4 subjects, but the decrease was not significant $(P=0.102)$ because three subjects in this group responded with an increase in PAI-1 activity (See Fig 2(b)). No difference between the periods was found in the E3/E3 homozygotes (individual results not shown). Minor changes of PAI-1 antigen concentrations 

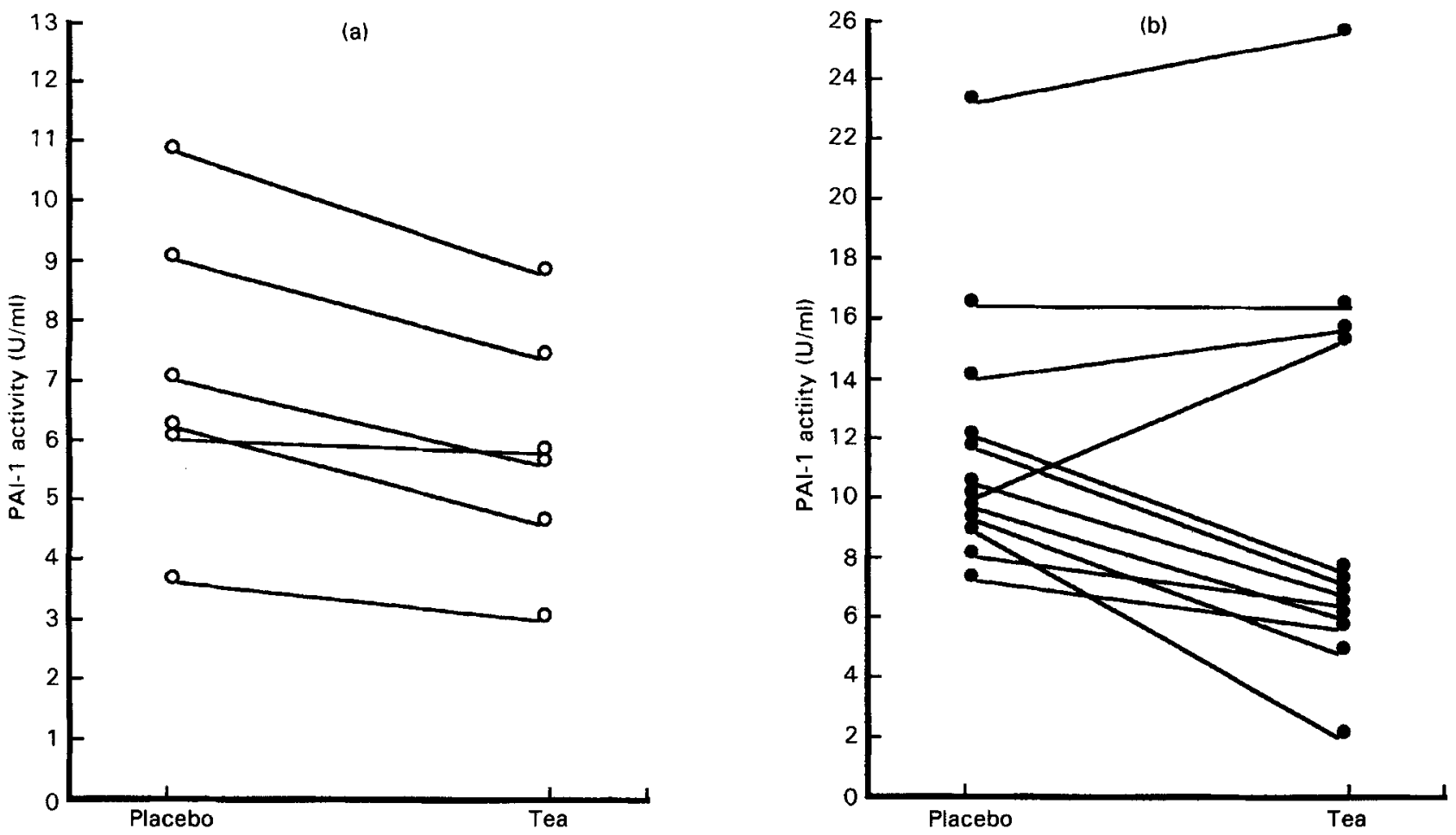

Fig. 2. Individual values for plasminogen activator inhibitor-1 (PAl-1) activity for subjects drinking six mugs of black tea or a placebo daily. (a) Subjects with the apolipoprotein E genotype E2/E3; (b) subjects with the apolipoprotein E genotypes E3/E4+E4/E4.

between the study periods failed to reach statistical significance in any genotype group.

\section{Discussion}

Intervention trials of free-living individuals are associated with a number of problems ranging from recruitment, noncompliance, selection of volunteers, to inevitable interindividual variation of multiple factors in any human population. One of the most important and often ignored (or unknown) factors is genetic heterogeneity illustrated by the present study.

This study was initially planned without considering any genetic component and designed with a potential power to reveal $5 \%$ or more differences in mean total plasma cholesterol between the intervention and control periods. Initial analyses performed for all sixty-five subjects of the study as a homogeneous group failed to reveal even minor differences in the cardiovascular disease risk factors assessed (Vorster et al. 1996; Bingham et al. 1997). ApoE genotyping was initiated at the Dunn Clinical Nutrition Centre after the study had been completed, and it was decided to reanalyse the results in relation to allele variants of the gene. Distribution of ApoE alleles detected in the present study was quite close to data reported for Caucasian populations by other authors (Schächter et al. 1994; Wilson et al. 1994; Dammerman \& Breslow, 1995; Bredie et al. 1996). As could be expected, grouping of the study subjects according to their ApoE genotypes resulted in one substantially bigger group of E3/E3 homozygotes and two smaller groups representing individuals with rarer allele variants. As a consequence of the smaller numbers in each group, the power to detect differences in means was decreased. Nevertheless, even with limited numbers of subjects, we were able to reveal several findings, previously undisclosed when the data were analysed without regard to ApoE genotype.

It is well known that the EA allele is associated with higher levels of total plasma cholesterol, LDL-cholesterol and triacylglycerols (Davignon et al. 1988; Dammerman \& Breslow, 1995), and our data provide another confirmation of this. Separate analyses of the effects of black tea drinking on blood lipids in the genotype groups failed to reveal statistically significant beneficial effects of tea drinking on cholesterol. HDL, rather than LDL, cholesterol was lowered to a small extent by tea drinking in the E3/E3 group, which would not reduce cardiovascular disease risk. There was no response in E4-bearing subjects.

There are many other risk factors involved in the pathogenesis of $\mathrm{CHD}$ including hypertension and haemostatic factors. Blood pressure was measured in the present study but no significant effect of tea drinking was seen in any of the allele types.

Fruits and vegetables also contain similar polyphenols to those in tea, and high consumption of fruits and vegetables has been previously reported to decrease PAI-1 activity (Nilsson et al. 1990). Tea might be expected to have an effect, but analyses carried out before information on the ApoE genotypes was available, failed to reveal any differences in blood clotting factors between placebo and tea drinking periods (Vorster et al. 1996). It should be noted that, while both elevated concentrations of fibrinogen (Kannel et al. 1987) and increased levels of PAI-1 and tPA (Paramo et al. 1985; Olofsson et al. 1989) are known 
cardiovascular disease risk factors, little was known of their possible interactions with ApoE genotype. We have demonstrated the existence of such links for the first time.

The most impressive results were obtained for PAI-1 activity (see Table 2). Subjects bearing the $\mathrm{E} 4$ allele, which is associated with the high cardiovascular disease risk, were found to have highest activities in contrast with the low risk E2/E3 group, which displayed the lowest levels. This finding suggests a new mechanism for the association between the presence of the $\mathrm{E} 4$ allele and increased cardiovascular disease risk.

In eight of the twelve individuals in the E4 group, PAI-1 activity fell, but it did not do so in four, so that overall there was no significant change $(P=0 \cdot 102$, Fig. 2(b)). However, tea drinking reduced PAI-1 activity in all E2/E3 subjects (Fig. 2(a)). This indicates that individuals with the E2 allele of ApoE may benefit from tea drinking, but mainly through its effects on the blood coagulation/fibrinolysis system rather than through modulation of blood cholesterol levels.

Furthermore there was a simultaneous decrease of triacylglycerol concentration brought about by tea drinking in the E2/E3 group. The results obtained in such small groups should be interpreted with care, but the E2 allele has been reported to decrease risk of CHD (Dammerman \& Breslow, 1995) and recently has been shown to be strongly associated with human longevity (Schächter et al. 1994). Elevated concentrations of plasma triacylglycerols are believed to be atherogenic by themselves (Patsch, 1993) and are typically associated with an increased PAI-1 activity. This combination constitutes an additional risk factor for myocardial infarction (Hamsten et al. 1987; Juhan-Vague \& Alessi, 1997). Our observations suggest that a higher system controlling concentrations of these factors in individuals possessing an E2 allele may exist and explain some of the protective effects of the E2 allele against cardiovascular disease.

The molecular mechanisms involved in interaction between isoforms of ApoE and the fibrinolysis system is a matter of hypothesis, but there is no doubt that these links exist (Jansen \& Reinders, 1992). One intriguing candidate for this role is LDL receptor-related protein, which is capable of binding several ligands including ApoE, tPA and PAI-1 (Bu et al. 1994; Rebeck et al. 1995). This matter remains to be clarified by further studies.

Due to the limited number of individuals tested in the E2 and E4 allele groups our results need confirmation in a larger study in which genotyping is introduced at the initial stage of volunteer selection. This would allow a larger number of participants with different genotype variants to be selected thus increasing statistical power. Nevertheless this study with tea has shown the importance of genetic characteristics in interaction with dietary factors. A new link between the ApoE-E4 allele and haemostatic cardiovascular disease risk factors has also been found.

\section{Acknowledgements}

The volunteers who took part in this study are thanked for their enthusiastic participation. Mrs Janet Beck is thanked for nursing expertise. This study was supported by the Tea Packer's Association and the Medical Research Council.

\section{References}

Bingham SA, Vorster H, Jerling JC, Magee E, Mulligan A, Runswick SA \& Cummings JH (1997) Effect of black tea drinking on blood lipids, blood pressure and aspects of bowel habit. British Joumal of Nutrition 78, 41-55.

Bredie SJH, Vogelaar JM, Demacker PNM \& Stalenhoef AFH (1996) Apolipoprotein E polymorphism influences lipid phenotypic expression, but not the low density lipoprotein subfraction distribution in familial combined hyperlipidemia. Atherosclerosis 126, 313-324.

Bu GJ, Maksymovitch EA, Nerbonne JM \& Schwartz AL (1994) Expression and function of low-density lipoprotein receptorrelated protein (LRP) in mammalian central neurons. Journal of Biological Chemistry 269, 18521-18528.

Castelli WP (1996) Lipids, risk factors and ischaemic heart disease. Atherosclerosis 124 Suppl., S1-S9.

Clauss A (1957) Gerinnungsphysiologissche Schellmetode zur Bestimmung des Fibrinogens (A quick fibrinogen determination method based on clotting physiology). Acta Haematologica 17, 237-246.

Dammerman M \& Breslow JL (1995) Genetic basis of lipoprotein disorders. Circulation 91, 505-512.

Davignon J, Cregg RE \& Sing CF (1988) Apolipoprotein E polymorphism and atherosclerosis. Arteriosclerosis 9, 405411.

Department of Health (1994) Nutritional Aspects of Cardiovascular Disease. Report on Health and Social Subjects no. 46. London: H.M. Stationery Office.

Hamsten A, De Faire U, Walldius G, Dahlen G, Szamosi A, Landou C, Blombäck, M \& Wiman B (1987) Plasminogen activator inhibitor in plasma: risk factor for recurrent myocardial infarction. Lancet ii, 3-8.

Hixson JE \& Vernier DT (1990) Restriction isotyping of human apolipoprotein $\mathrm{E}$ by gene amplification and cleavage with $\mathrm{Hhal}$. Journal of Lipid Research 31, 545-548.

Jansen JWCM \& Reinders JH (1992) Fibrinolysis: system and processes. Coronary Artery Disease 3, 425-434.

Juhan-Vague I \& Alessi MC (1997) PAI-1, obesity, insulin resistance and risk of cardiovascular events. Thrombosis and Haemostasis 78, 656-660.

Kamboh MI, Aston CE \& Hamman RF (1995) The relationship of APOE polymorphism and cholesterol levels in normoglycemic and diabetic subjects in a biethnic population from the San Luis Valley, Colorado. Atherosclerosis 112, 145-159.

Kannel WB, Wolf PA, Castelli WP \& D'Agostino RB (1987) Fibrinogen and risk of cardiovascular disease. The Framingham study. Journal of the American Medical Association 258, 11831186.

Kontula K, Aalto-Setälä K, Kuusi T, Hämäläinen L \& Syvänen A-C (1990) Apolipoprotein E polymorphism determined by restriction enzyme analysis of DNA amplified by polymerase chain reaction: convenient alternative to phenotyping by isoelectric focusing. Clinical Chemistry 36, 2087-2092.

Mahley RW (1988) Apolipoprotein E: cholesterol transport protein with expanding role in cell biology. Science 240 , 622-630.

Manttari M, Koskinen P, Enholm C, Huttunen JK \& Manninen V (1991) Apolipoprotein E polymorphism influences the serum cholesterol response to dietary intervention. Metabolism 40, 217-221.

Marshall JA, Kamboh MI, Bessesen DH, Hoag S, Hamman RF \& Ferrell RE (1996). Associations between dietary factors and serum lipids by apolipoprotein E polymorphism. American Journal of Clinical Nutrition 63, 87-95.

Nakata Y, Katsaya T, Rakugi H, Takami S, Ohishi H, Kamino K, Higaki J, Tabuchi Y, Kimahara Y, Miki T \& Ogihara T (1996) 
Polymorphism of the apolipoprotein-E and angiotensinconverting enzyme genes in Japanese subjects with silent myocardial ischemia. Hypertension 27, 1205-1209.

Nilsson TK, Sundell IB, Hellsten G \& Hallmans G (1990) Reduced plasminogen activator inhibitor activity in high consumers of fruits, vegetables and root vegetables. Journal of Internal Medicine 227, 267-271.

Olofsson BO, Dahlen G \& Nilsson TK (1989) Evidence for increased levels of plasminogen activator inhibitor and tissue plasminogen activator in plasma of patients with angiographically verified coronary artery disease. European Heart Journal 10, 77-82.

Paik Y-K, Chang DJ, Reardon CA, Davies GE, Mahley RW \& Taylor JM (1985). Nucleotide sequence and structure of the human apolipoprotein E gene. Proceedings of the National Academy of Sciences USA 82, 3445-3449.

Paramo JA, Colucci M, Collen D \& van de Werf F (1985) Plasminogen activator inhibitor in the blood of patients with coronary heart disease. Lancet 291, 573-574.

Patsch JR (1993) Is hypertriglyceridemia atherogenic? Atherosclerosis Reviews 25, 331- 339.

Rebeck GW, Harr SD, Strickland DK \& Hyman BT (1995) Multiple, diverse senile plaque-associated proteins are ligands of an apolipoprotein E receptor, the Alpha(2)-macroglobulin receptor low-density-lipoprotein receptor protein. Annals of Neurology 37, 211-217.

Routi T, Rönnemaa T, Salo P, Seppänen R, Marniemi J, Viikari J, Enholm C \& Simell O (1996) Effects of prospective, randomized cholesterol-lowering dietary intervention and apolipoprotein $\mathrm{E}$ phenotype on serum lipoprotein(a) concentra- tions of infants aged 7-24 mo. American Journal of Clinical Nutrition 63, 386-391.

Schächter F, Faure-Delanef L, Guénot F, Rouger H, Froguel P, Lesueur-Ginot L \& Cohen D (1994) Genetic associations with human longevity at the APOE and ACE loci. Nature Genetics 6, 29-32.

Scheer WD, Boudreau DA, Malcolm GT \& Middaugh JP (1995) Apolipoprotein $\mathrm{E}$ and atherosclerosis in Alaska Natives. Atherosclerosis 114, 197-202.

Vorster $\mathrm{H}$, Jerling J, Oosthuizen $\mathrm{W}$, Cummings J, Bingham S, Magee L, Mulligan A \& Runswick S (1996) Tea drinking and haemostasis: a randomised, placebo controlled, cross over study in free living subjects. Haemostasis 26, 58-64.

Weisgraber KH \& Mahley RW (1996) Human apolipoprotein E: the Alzheimer's disease connection. FASEB Journal 10, 1485 1494.

Wenham PR, Price WH \& Blundell G (1991) Apolipoprotein E genotyping by one-stage PCR. Lancet 337, 1158-1159.

Wilson PF, Myers RH, Larson MG, Ordovas JM, Wolf PA \& Schaefer EJ (1994) Apolipoprotein E alleles, dyslipidemia and coronary heart disease. The Framingham Offspring Study. Journal of the American Medical Association 272, 1666-1671.

Wilson PWF, Schaeffer EJ, Larson MG \& Ordovas JM (1996) Apolipoprotein-E alleles and risk of coronary disease - a metaanalysis. Arteriosclerosis, Thrombosis and Vascular Biology 16, 1250-1255.

Xu CF, Boerwinkle E, Tikkanen MJ, Huttunen JK \& Manninen V (1990) Genetic variation at the apolipoprotein loci contribute to response of plasma lipids to dietary change. Genetic Epidemiology 7, 261-275. 